\title{
Effect of Seismic Isolation with Triple Friction Pendulum Isolator Device on Weight Optimization of Steel Plane Frames
}

\author{
Refik Burak Taymuş ${ }^{a *}$, İbrahim Aydoğdu ${ }^{b}$ \\ ${ }^{a}$ Department of Civil Engineering, Van 100. Yll University, Van, Turkey \\ ${ }^{b}$ Department of Civil Engineering, Akdeniz University, Antalya, Turkey \\ ${ }^{*}$ E-mail address: refikburaktaymus@yyu.edu.tr ${ }^{{ }^{*}}$, aydogdu@,akdeniz.edu.tr ${ }^{\mathrm{b}}$
}

ORCID numbers of authors:

0000-0002-1489-9307 *, 0000-0002-8281-2365

Received date: 16.09.2021

Accepted date: 25.10.2021

\begin{abstract}
In the study, the weight efficiency of the Triple Friction Pendulum Bearing (TFP) Isolators is investigated on optimal weight of planar steel frames. For this investigation, an optimization program based on Artificial Bee Colony $(A B C)$ algorithm have been developed for this study. In the design of steel frames, the structure should satisfy strength, inter-story drift, top-story drift and geometric requirements that are implemented from LRFDAISC. For the research, 8 different planar frames were optimized as seismic-isolated and fixed-based, which were diversified according to story height and bracing. According to the results, the frames with TFP isolators, especially non-braced ones are a lot more advantageous regarding the optimal weight.
\end{abstract}

Keywords: Triple friction pendulum isolator, Planar steel frame, Bracing, Seismic-isolated, Artificial bee colony algorithm

\section{Introduction}

Minimizing the damaging effects of earthquakes on the structure is one of the most popular fields of study in structural engineering. Various structural design methods are used for this purpose. One of the methods is seismic isolation of the structures. Isolator devices increase the period of the superstructure and thus decrease the earthquake-resulted story drifts and ground accelerations acting to the floors, which means that earthquake-induced deformations are mitigated. On the other hand, it should also be considered that seismic isolation can have a reducing effect on the cost of the superstructure because it can allow the dimensions of the structural elements to be smaller than those of traditional design. To investigate this effect, it is necessary to conduct a comparative study of seismic-isolated structures and fixed-based structures in terms of cost. It is very difficult to make this comparison with conventional methods and does not give a realistic result. In this context, the metaheuristic optimization techniques are effective methods for realistic comparison. Metaheuristic optimization techniques with swarm intelligence present consistent solutions to complex optimization problems [1-6]. Swarm intelligence is based on the resolution of problems in nature as a swarm rather than as an individual. Metaheuristic optimization algorithms are created by simulating the behavior of the swarm while it is foraging. Many metaheuristic optimization algorithms such as Genetic algorithm, Archimedean optimization algorithm, and Crow search algorithm 
have been developed and successfully applied to complex optimization problem so far, and artificial bee colony algorithm (ABC) is one of these algorithms. $\mathrm{ABC}$ algorithm which simulates the foraging behavior of honey bees, performed well in structural optimization problems for optimal sizing of truss and frame structures [7-8].

In literature, there are many optimization studies related to seismic isolated structures. Skandalos et al. [9] conducted a comparative optimization study in terms of seismic response on fixed-based, base-isolated, and inter-story isolated structures. Tsipianitis and Tsompanakis [10] tried to optimize the seismic response of a seismic-isolated liquid storage tank by using swarm intelligence algorithms and used single friction pendulum and triple friction pendulum isolators from sliding-based isolator devices. In the study, dimensional parameters of the isolator devices were also optimized as well as the seismic response of the superstructure. In a study conducted by Çerçevik et al. [11], isolator period and damping ratio of seismic isolation systems were optimally designed by using metaheuristic search methods in a way to minimize the roof acceleration. Peng et al. [12] optimized an adaptive sliding base isolation system to prevent possible failure of isolator devices during an extreme ground motion and thus to improve the seismic performance of structures. Rizzian et al. [13] presented a study on sizing optimization of seismic isolated reinforced concrete structures where optimum design main parameters were superstructure material cost, top floor displacement, and acceleration and it was revealed that when the cost of seismic isolator devices was considered, base isolation did not provide a cost advantage to the structure in total while it had positive effects in top floor response and acceleration. In a study that Jiang et al. [14] conducted, isolator devices used in seismic-isolated simply supported bridge model in the near-fault region was optimized by considering the pulse effect.

Related to the papers mentioned above, it can be commented that there are not enough studies to observe the effect of seismic isolation regarding the cost of the superstructure. In this context, this paper contributes to the literature. The paper presents a comparative study of cost optimization of base-isolated and fixed-base structure models. Accordingly, four different examples are designed: (i) 4-story 2D steel frame with braces, (ii) 4-floor 2D steel frame without braces, (iii) 8-floor 2D steel frame with braces, (iv) 8-floor 2D steel frame without braces. Each of the examples is handled as both seismic-isolated and fixed-based. Triple friction pendulum (TFP) isolator devices are used for seismic isolation of the models. All the models are optimized by using $\mathrm{ABC}$ algorithm and the results from seismic-isolated models are compared to those from fixed-based ones.

\section{Optimum Design of Steel Plane Frames}

To optimally design steel frames, it is necessary to select frame member sections from a suitable steel section list in a way to satisfy specified limitations and serviceability by considering that the main objective of the design is to minimize the material cost of the frame. It is well-known that the material cost of a superstructure is proportional to its weight. Thus, the main function of the design can be given as in Eq. (1) [7].

$$
W(\vec{x})=\sum_{r=1}^{N G} m_{r} \cdot \sum_{S=1}^{t_{r}} l_{S}
$$

Here, $\vec{x}, W(\vec{x}), m_{r}, t_{r}, N G$, and $I_{s}$ respectively refer to a vector of the sequence number of Wsections selected for member groups, the weight of frame as a function of the selected sections, 
unit weight of frame section to use for group $r$, total member number of group $r$, total group number of frame, and member length of the member of group $r$. In the design, three different constraints are applied: (i) strength constraints, (ii) lateral drift constraints, and (iii) geometric constraints. Firstly, strength constraints to be complied with for each element of the frame are as in Eq. (2) [7].

$$
g_{S}(\vec{x})=\left\{\begin{array}{lll}
\frac{P_{u}}{\phi P_{n}}+\frac{8}{9} \frac{M_{u}}{\phi M_{n}}-1 \leq 0 & \text { if } & \frac{P_{u}}{\phi P_{n}} \geq 0.2 \\
\frac{P_{u}}{2 \phi P_{n}}+\frac{M_{u}}{\phi M_{n}}-1 \leq 0 & \text { if } & \frac{P_{u}}{\phi P_{n}}<0.2
\end{array}\right.
$$

Here, $M_{n}, M_{u}, P_{n}$, and $P_{u}$ respectively refer to, a nominal flexural strength of the frame, design moment, nominal axial strength, and design axial force for the structural element. $M_{u}$ value is computed according to the second-order analysis of the structure. In the study, the approximate method specified in part C of the LRFD-AISC [15] specification was used for the second-order analysis.

Secondly, constraint functions of top and inter-story drift constraints are presented Eqs. (3)-(4) [7].

$$
\begin{gathered}
g_{i d}(\vec{x})=\frac{\Delta_{j l}^{s t r}}{h_{s x} / \text { Ratio }}-1 \leq 0 \quad j=1,2, \ldots, n_{s t} \quad l=1,2, \ldots, n_{l c} \\
g_{t d}(\vec{x})=\frac{\Delta_{j l}^{\text {top }}}{H / \text { Ratio }}-1 \leq 0 \quad j=1,2, \ldots, n_{j t o p} \quad l=1,2, \ldots, n_{l c}
\end{gathered}
$$

Here, $n_{l c}, H, n_{j t o p}, \Delta_{j l}^{t o p}, \Delta_{j l}^{s t r}, n_{s t}, h_{s x}$, Ratio are load-case number, height of frame, joint number of top story, $j^{\text {th }}$ joint $/ l^{\text {th }}$ load-case top story displacement, $j^{\text {th }}$ story $/ l^{\text {th }}$ load-case story drift, story number, story height, and lateral displacement limitation ratio from ASCE Ad Hoc Committee report [16]. This report has presented that lower and upper bounds of Ratio values are $1 / 750 H$ and $1 / 250 H$ for top story drift, and $1 / 500 h_{s x}$ and $1 / 200 h_{s x}$ for inter-story drift.

Finally, geometric constraints are explained in Eq. (5)-(6) [7].

$$
\begin{gathered}
g_{c c}(\vec{x})=\sum_{i=1}^{n_{c c j}}\left(\frac{D_{i}^{a}}{D_{i}^{b}}-1\right)+\sum_{i=1}^{n_{c c j}}\left(\frac{m_{i}^{a}}{m_{i}^{b}}-1\right) \leq 0 \\
g_{b c}(\vec{x})=\sum_{i=1}^{n_{j 2}}\left(\frac{B_{f}^{b i}}{B_{f}^{c i}}-1\right) \leq 0
\end{gathered}
$$

Here, $n_{c c j}, m_{i}^{a}, m_{i}^{b}, D_{i}^{a}, D_{i}^{b}, n_{j 2}, D^{c i}, t_{b}^{c i}, B_{f}^{c i}$, and $B_{f}^{b i}$ respectively refer to unit weight of above story-W section, unit weight of below story-W section, depth of above story-W section, 
depth of below story-W section, number of beam-column connection joints, depth of columnW section at the joint $i$, flange thickness of column-W section at the joint $i$, flange width of column-W section at the joint $i$, flange width of column-W section at joint $i$, and flange width of beam-W section at the joint $i$. Fig. 1 describes these parameters.

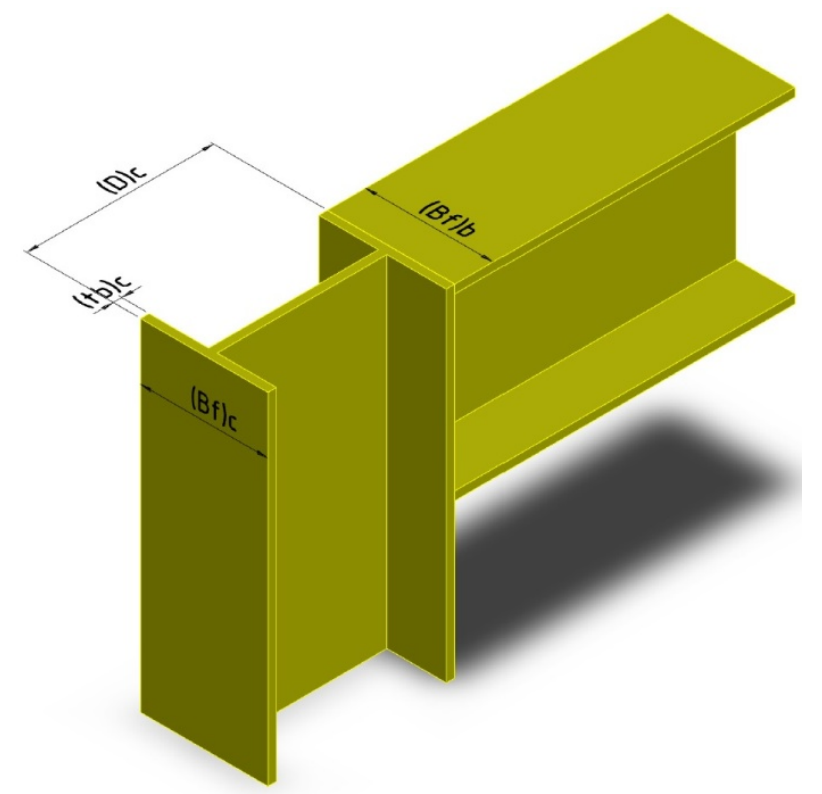

(a)

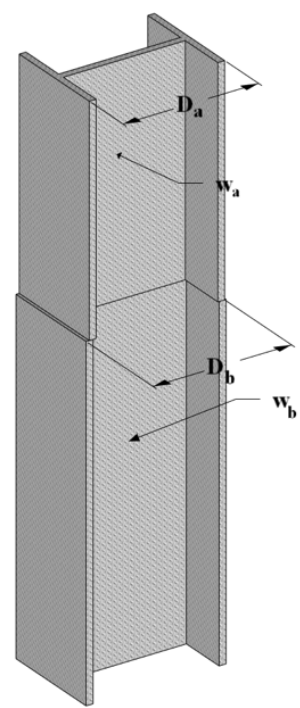

(b)

Fig. 1. (a) Beam-Column, (b) Column-Column connections and constraint parameters

During the optimization process, if the candidate frame design does not satisfy Eq. (2)-(6), the weight of the structure design increases with the penalty function. The static penalty function (see Eq. (7)), which is frequently used in frame optimization problems, is preferred in the study.

$$
W_{p}=W \cdot(1+P)^{\varepsilon}
$$

Here, $W p$ is the penalized weight, $P$ is the total penalty value and $\varepsilon$ is the penalty coefficient ( $\varepsilon=2$ in this study). $\varepsilon$ value was considered as 2 in [7] and this value was found to be effective. For this reason, it will be considered as $\varepsilon=2$ in this study. The value of $P$ is calculated by Eq. (8) [7].

$$
P=\sum_{i=1}^{N C} C_{i} \quad \text { and } C_{i}=\left\{\begin{array}{ll}
0 & \text { if } \quad g_{i}(\vec{x}) \leq 0 \\
g_{i}(\vec{x}) & \text { if } \quad g_{i}(\vec{x})>0
\end{array}\right\}
$$

Here, subscript $i$ represents any constraint function, NC is the total number of constraint functions in the optimization problem. In the study, the fitness value of the candidate solution (Fit) is inversely proportional to penalized weight and is formulated in Eq. (9). 


$$
\text { Fit }=\frac{1}{W_{p}}
$$

\section{Artificial Bee Colony (ABC) Algorithm}

The ABC method was first developed by Karaboga and Basturk [17-23] by observing the behaviors of bees for minimum energy expenditure during foraging. The method categorizes worker bees as employed, onlooker, and scout bees. Employed bees handle collecting pollens from nectar sources ( $N S$ 's) and sharing information about $N S$ with the colony. Onlooker bees decide to fly $N S$ according to information shared from the employed bees. In the case of a depleted NS, scout bees look for new NS instead of depleted sources. In each cycle of the ABC, the employed bees choose one $N S$, and the onlooker bees have the same total number of flights as the worker bees. The scout bees replace the worker bee that flies to the depleted NS. Therefore, in the method, the numbers of employed bees, onlooker bees, and $N S$ are equal. In the method, the $N S$, the location of the $N S$, and the quality of the $N S$ represent the candidate solution, the design variables, and the fitness of the solution respectively. The optimization process of the $\mathrm{ABC}$ algorithm can be explained in these steps:

(i) The algorithm constitutes initial designs randomly by Eq. (10).

$$
\vec{x}_{p i}=x_{l i}+\alpha_{p}\left(\vec{x}_{u i}-\vec{x}_{l i}\right) \quad \alpha_{p} \in[0,1] \quad i=1,2, \ldots, n \quad p=1,2, \ldots, p n
$$

Here, $\alpha_{p}, n, p n$ is respectively a random value between 0 and 1 , element number of solution

vector, and the number of NS. $\overrightarrow{x_{u i}}$ and $\overrightarrow{x_{l i}}$ are respectively upper and lower bounds of $x_{i}$. The algorithm evaluates the initial design, finds their fitness values, and assigns the trial values to the initial design as zero. All these values are stored in the algorithm memory.

(ii) Worker bees modify designs in the memory as in Eq. (11).

$$
\vec{x}_{p i}=\vec{x}_{p i}+\beta_{p}\left(\vec{x}_{p i-} \vec{x} k i\right) \quad \beta_{p} \in[-1,1] \quad k \neq i \quad i=1,2, \ldots, n
$$

Here, $x_{k i}$ is a randomly selected NS and $\beta_{p}$ is a random value between -1 and 1 . Then the $\mathrm{ABC}$ computes the fitness values of the new designs and compares them with the old designs. The new design replaces the old one if the new designs have better fitness. Otherwise, the old solution stays in memory and its trial value increased by one. This process is named as "greedy selection".

(iii) Onlooker bees figure out the designs to modify based on the information received from the worker bees. This decision must be based on a probability value, named as $P V_{p}$, calculated by Eq. (12).

$$
P V_{p}=\frac{F i t\left(x_{p}\right)}{\sum_{p=1}^{p n} F i t\left(x_{p}\right)}
$$


After the decision, the algorithm performs the same procedures to decided designs as in the worker bee part.

(iv) If the trial number of the design is greater than the limit value defined at the beginning of the optimization process, scout bees step in. Scout bees remove the design from the memory and find the new design in the same way with step (i).

After step (iv), the algorithm completes one cycle and goes back to step (ii). The algorithm performs operations between steps (ii) and step (iv) until it reaches the maximum cycle number and/or function evaluation number.

\section{The Design of Triple Friction Pendulum Bearing (TFP) Isolators}

TFP isolators are a type of frictional-based seismic isolator devices and are commonly used in seismic isolation of structures (see Fig. (2)). They are composed of 5 components: (i) Top concave sliding plate $\left(\mathrm{C}_{1}\right)$, (ii) Bottom concave sliding plate $\left(\mathrm{C}_{2}\right)$, (iii) Top concave slider $\left(\mathrm{C}_{3}\right)$, (iv) Bottom concave slider $\left(\mathrm{C}_{4}\right)$, and (v) Inner articulated slider $\left(\mathrm{C}_{5}\right)$. Figure 2 describes TFP's components and parameters. For the concave surfaces, it must be $R_{1}=R_{4}$ and $R_{2}=R_{3}$ and likewise $d_{1}=d_{4}$ and $d_{2}=d_{3}$ for the displacement capacities. There are four frictional interaction surfaces between the components. The friction coefficients of the surfaces are $\mu_{1}, \mu_{2}, \mu_{3}$, and $\mu_{4}$, from the bottom to the top, respectively and generally $\mu_{2}=\mu_{3}<\mu_{1}=\mu_{4}$ or $\mu_{2}=\mu_{3}<\mu_{1}$ $<\mu_{4}$. In this study, it is taken as $\mu_{2}=\mu_{3}<\mu_{1}=\mu_{4}$.

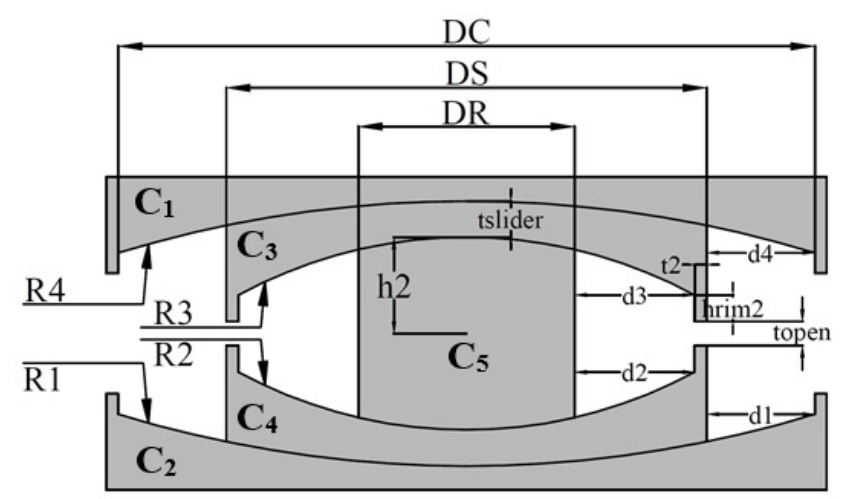

Fig. 2. A TFP model and its parameters

TFP isolator devices to use in this study are designed by abiding by "LRFD-Based Analysis and Design Procedures for Bridge Bearings and Seismic Isolators" [24]. $D C$ and $R_{l}$ values required for the design are given in Table 1, quoting from section 4.4 of [24]. Considering the values selected from Table 1, $d_{l}$ and then $D S$ can be calculated by Eq. (13)-(14).

$$
\begin{gathered}
d_{1}=0.15 D C \\
D S=D C-2 d_{1}
\end{gathered}
$$

Table 1. R1 and DC parameter values of friction pendulum bearings [23]

\begin{tabular}{|c|c|c|c|c|c|c|c|c|c|c|c|c|c|c|}
\hline$R_{I}$ (inch) & 61 & 61 & 61 & 61 & 61 & 88 & 88 & 88 & 88 & 88 & 88 & 88 & 88 & 88 \\
\hline$D C$ (inch) & 14 & 18 & 22 & 31 & 36 & 27 & 31 & 36 & 39 & 41 & 44 & 46 & 51 & 56 \\
\hline
\end{tabular}


After the calculation of $D S$, axial pressure, $p_{1}$, of a concave slider to concave sliding plate is obtained by Eq. (15).

$$
p_{1}=\frac{W}{\frac{\pi \cdot D S^{2}}{4}}
$$

Here, $W$ is an axial load on the isolator device and its unit must be kips. Friction coefficients are proportional to axial pressure and the $\mu_{1}$ value is calculated by Eq. (16) as based on $p_{1}$.

$$
\mu_{1}=0.122-0.01 p_{1}
$$

In this design, it is considered that the $\mu_{1}$ value is better to be equal to 0.05 or larger than 0.05 . If $\mu_{1}<0.05$, the above process must be repeated with new $R_{l}$ and $D C$ values until $\mu_{1} \geq 0.05$. Moreover, the $\mu_{2}$ value is 30 percent of the $\mu_{1}$ value. With the calculation of $\mu_{2}$, if Eq. (16) is rearranged with respect to $\mu_{2}$, Eq. (17) can be derived by subtracting $p_{2}$ from the new equation rearranged.

$$
p_{2}=\frac{0.122-\mu_{2}}{0.01}
$$

Here, $p_{2}$ is the axial pressure of the articulated slider to the concave slider. $t_{2}, t_{\text {slider }}$, and $h_{\text {rim } 2}$ parameters are obtained as respectively $D S / 30, D S / 7$, and $D S / 20$ for this study. In the next step, applying Eq. (15) for $p_{2}$, Eq. (18) is obtained.

$$
p_{2}=\frac{W}{\frac{\pi \cdot D R^{2}}{4}}
$$

And thus, $D R$ value can be attained by Eq. (19).

$$
D R=\sqrt{\frac{4 W}{\pi \cdot p_{2}}}
$$

$D R$ value is wished to be larger than $0.25 D S$ and smaller than $0.5 D S$. If these boundary conditions exceed, all the processes must be repeated from the beginning. The calculation of $D R$ value leads up to $d_{2}$ (See Eq. (20)).

$$
d_{2}=\frac{D S-D R-2 t_{2}}{2}
$$

In the design, the distance between the closest endpoints of the support in the vertical direction is 1 inch. According to this, the $h_{2}$ value can be geometrically obtained by Eq. (21). 


$$
h_{2}=R_{2}-\sqrt{R_{2}^{2}-\left(\frac{D S}{2}-t_{2}\right)^{2}}+h_{\text {rim } 2}+\frac{t_{\text {open }}}{2}
$$

Finally, $h_{1}$ value is calculated as related to $h_{2}$ and $t_{\text {slider }}$ by Eq. (22).

$$
h_{1}=h_{2}+t_{\text {slider }}
$$

\section{Design of Steel Plane Frames}

This study aims to evaluate the effect of seismic isolation on weight by optimizing seismic isolated and fixed-based steel plane frame samples using the $\mathrm{ABC}$ optimization algorithm. For this goal, four steel plane frame examples, two of which have 4-story and the other two have 8story, are designed. All 4-story and 8-story frames are modeled both with and without braces. Frame members are grouped as: one group for outer columns in every 4 floors, one group for inner columns in every 4 floors, one group for beams in every 4 floors, one group for braces in each floor. Joint, member, and group number of the frames are given in Table 2. The member grouping of all the frame examples are handled as both fixed-based and seismic-isolated (see Fig. (3-6)). The profiles to be assigned to the member groups are selected from the $\mathrm{W}$ sections from W150X13 to W920X1191 as given in LRFD-AISC. In seismic-isolated frames, 3 members are added to the base floor for 4-story frames and 5 members for 8-story frames to provide the lateral stability of isolator devices. The vertical loads applied to the frames are 2.88 $\mathrm{kN} / \mathrm{m}^{2}$ of dead load (D), $2.39 \mathrm{kN} / \mathrm{m}^{2}$ of live load (L), and $0.755 \mathrm{kN} / \mathrm{m}^{2}$ of snow load (S). The equivalent earthquake loads for each story are acted on both $X$ and $Y$ directions (EX and EY) and re-calculated in each iteration of the optimum design. The design load combinations are $1.4 \mathrm{D}, 1.2 \mathrm{D}+1.6 \mathrm{~L}+0.5 \mathrm{~S}, 1.2 \mathrm{D}+0.5 \mathrm{~L}+1.6 \mathrm{~S}, 1.2 \mathrm{D}+0.5 \mathrm{~L}+0.2 \mathrm{~S}+1.0 \mathrm{EX}$, and $1.2 \mathrm{D}+0.5 \mathrm{~L}+$ $0.2 \mathrm{~S}+1.0 \mathrm{EY}$. Top-story and inter-story drift limitations are taken as respectively $H / 300$ and $h_{i} / 300$, which $H$ is the height of frame and $h_{i}$ is the height of $i^{\text {th }}$ story. The vertical loads, the drift limitations, and the load combinations are calculated by obeying to LRFD-AISC.

Table 2. Group and joint number of frame models

\begin{tabular}{|c|c|c|c|c|c|c|c|c|}
\cline { 2 - 9 } \multicolumn{1}{c|}{} & \multicolumn{4}{c|}{ 4-Story Frame Models } & \multicolumn{3}{c|}{ 8-Story Frame Models } \\
\cline { 2 - 9 } \multicolumn{1}{c|}{} & \multicolumn{3}{c|}{ FB } & \multicolumn{2}{c|}{ SI } & \multicolumn{2}{|c|}{ FB } & \multicolumn{2}{|c|}{ SI } \\
\hline Joint & WB & WOB & WB & WOB & WB & WOB & WB & WOB \\
Member & 44 & 20 & 24 & 20 & 70 & 54 & 70 & 54 \\
Group & 7 & 3 & 47 & 31 & 152 & 88 & 157 & 93 \\
\hline & WB: with braces & 7 & 3 & 14 & 6 & 14 & 6 \\
\hline
\end{tabular}




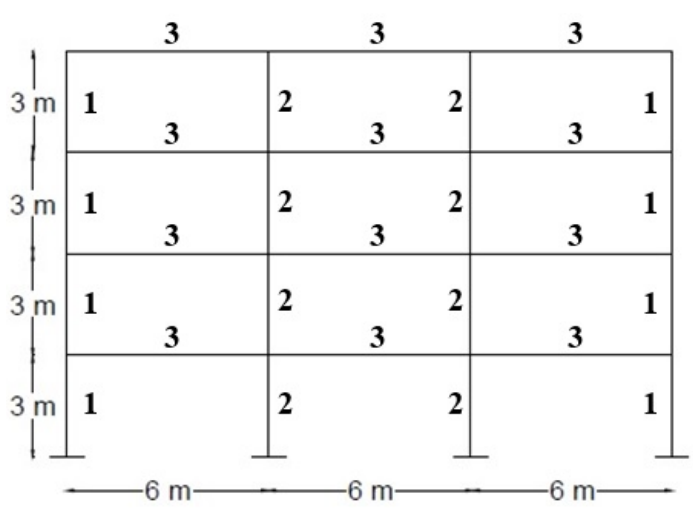

(a)

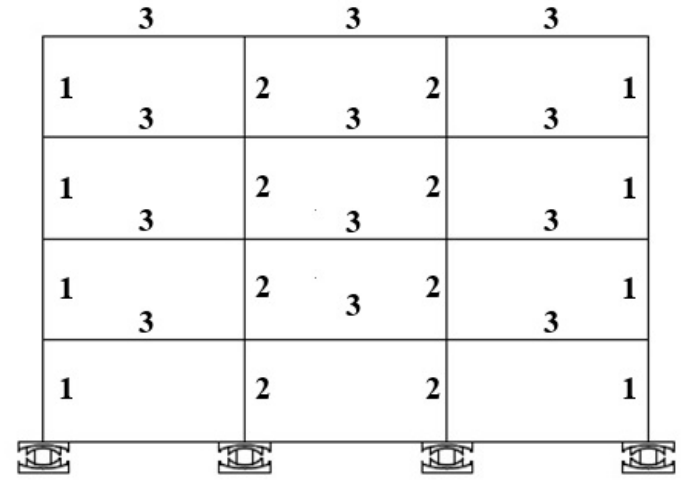

(b)

Fig. 3. Element group number for (a) Fixed-Based, (b) Seismic-Isolated 4-Story Model without Braces

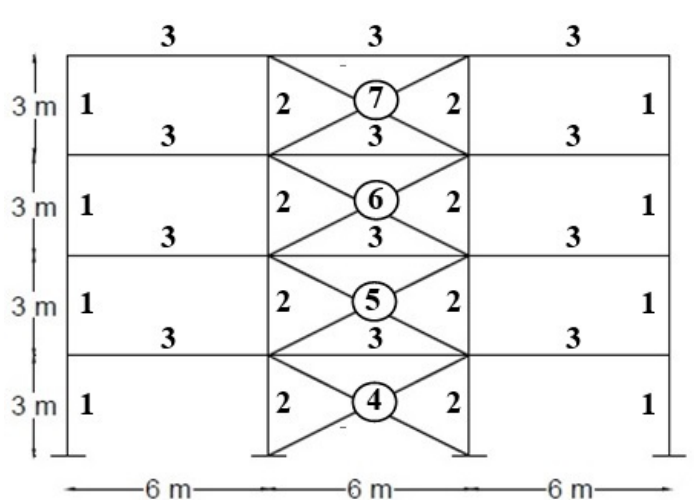

(a)

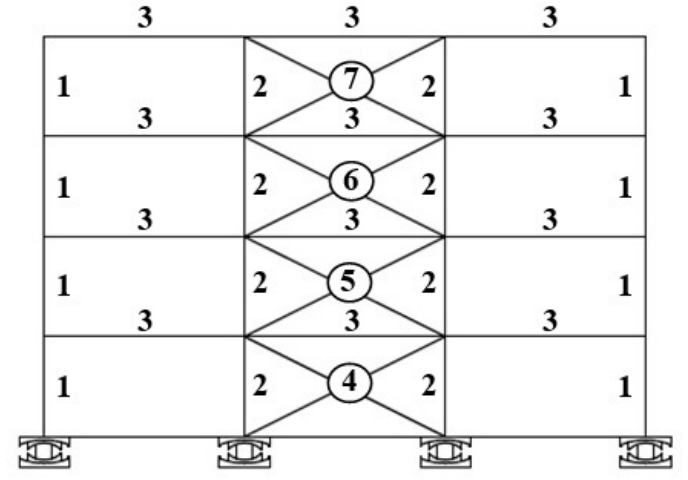

(b)

Fig. 4. Element group number for (a) Fixed-Based, (b) Seismic-Isolated 4-Story Model with Braces

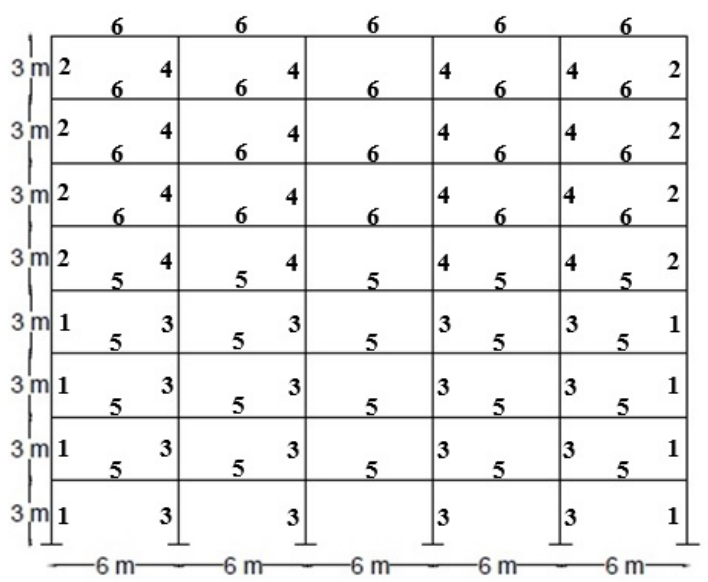

(a)

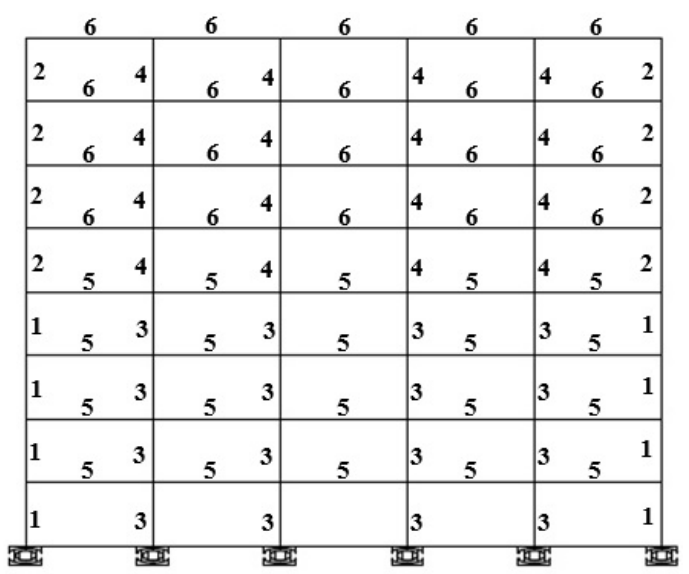

(b)

Fig. 5. Element group number for (a) Fixed-Based, (b) Seismic-Isolated 8-Story Model without Braces 


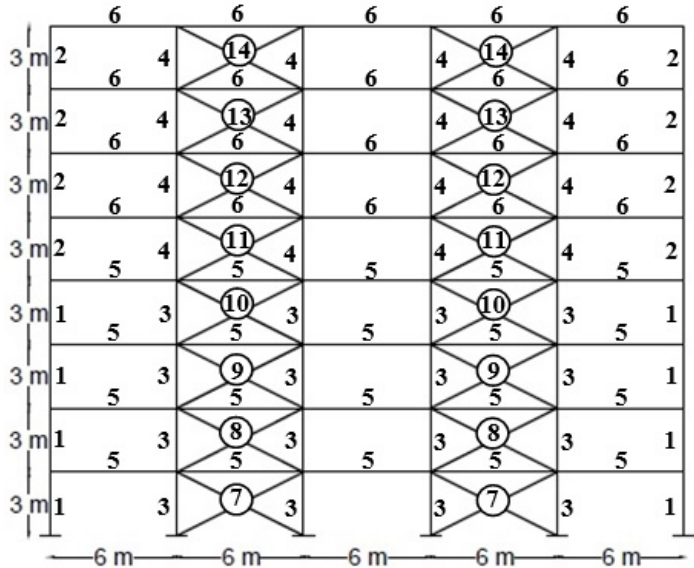

(a)

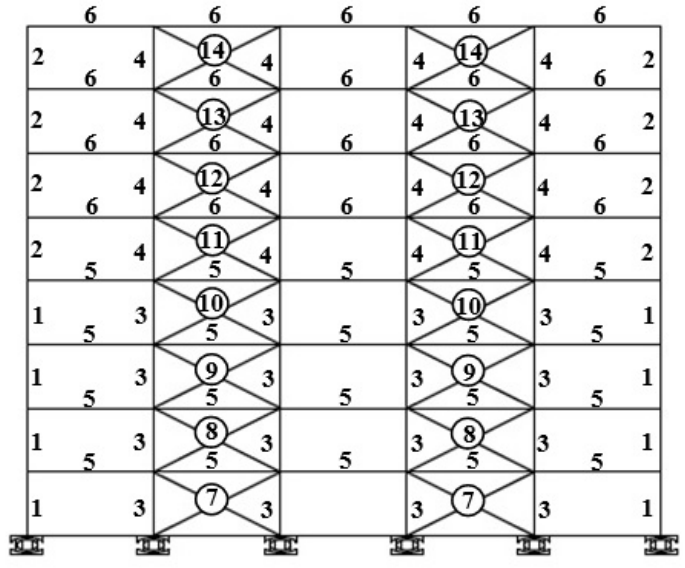

(b)

Fig. 6. Element group number for (a) Fixed-Based, (b) Seismic-Isolated 8-Story Model with Braces

All the design examples are optimized by using ABC algorithm. Section lists of the optimum designs are given in Tables 3-6. Moreover, the maximum constraint values, which are minimum weight, PMM ratios, maximum story drifts, maximum total drifts, and maximum number of iterations, computed at optimized design for the design examples are presented in Table 7. Considering the weight values determined, it can be seen that the seismic isolation decreases the weight by: $28.45 \%$ for 4 -story model without braces, $6.44 \%$ for 4 -story model with braces, and $22.43 \%$ for 8 -story without braces, $9.45 \%$ for 8 -story model with braces. The design histories are shown in Fig. (7)-(10). It is clearly seen from the figures that $\mathrm{ABC}$ algorithm has sufficient convergence rate.

Table 3. The best design weights for 4-story frame models without braces

\begin{tabular}{|c|c|c|}
\hline \# of Group & Fixed-Based & Seismic-Isolated \\
\hline 1 & W410X46.1 & W250X17.9 \\
2 & W410X46.1 & W310X32.7 \\
3 & W310X38.7 & W250X32.7 \\
\hline
\end{tabular}

Table 4. The best design weights for 4-story frame models with braces

\begin{tabular}{|c|c|c|}
\hline \# of Group & Fixed-Based & Seismic-Isolated \\
\hline 1 & W150X22.5 & W150X18 \\
2 & W200X31.3 & W200X26.6 \\
3 & W130X23.8 & W130X23.8 \\
4 & W200X19.3 & W100X19.3 \\
5 & W150X18 & W150X13 \\
6 & W150X13 & W200X15 \\
7 & W150X13 & W150X13.5 \\
\hline
\end{tabular}

Table 5. The best design weights for 8-story frame models without braces

\begin{tabular}{|c|c|c|}
\hline \# of Group & Fixed-Based & Seismic-Isolated \\
\hline 1 & W360X39 & W460X52 \\
2 & W360X39 & W250X28.4 \\
3 & W410X67 & W410X60 \\
4 & W410X53 & W310X32.7 \\
5 & W410X53 & W310X44.5 \\
6 & W360X51 & W250X32.7 \\
\hline
\end{tabular}


Table 6 . The best design weights for 8 -story frame models with braces

\begin{tabular}{|c|c|c|}
\hline \# of Group & Fixed-Based & Seismic-Isolated \\
\hline 1 & W200X26.6 & W360X39 \\
2 & W200X22.5 & W150X24 \\
3 & W460X74 & W360X51 \\
4 & W360X39 & W150X37.1 \\
5 & W150X22.5 & W130X23.8 \\
6 & W200X26.6 & W200X31.3 \\
7 & W250X32.7 & W310X23.8 \\
8 & W150X29.8 & W150X22.5 \\
9 & W310X38.7 & W250X22.3 \\
10 & W310X32.7 & W150X18 \\
11 & W150X29.8 & W310X23.8 \\
12 & W200X26.6 & W250X17.9 \\
13 & W150X13 & W100X19.3 \\
14 & W310X21 & W250X17.9 \\
\hline
\end{tabular}

Table 7. Maximum constraint values computed at optimized design for design examples

\begin{tabular}{|c|c|c|c|c|c|c|c|c|}
\cline { 2 - 9 } \multicolumn{1}{c|}{} & \multicolumn{4}{c|}{ 4-Story } & \multicolumn{4}{c|}{ 8-Story } \\
\cline { 2 - 9 } \multicolumn{1}{c|}{} & w Braces & w/o Braces & \multicolumn{2}{c|}{ w Braces } & w/o Braces \\
\cline { 2 - 9 } \multicolumn{1}{c|}{} & FB & SI & FB & SI & FB & SI & FB & SI \\
\hline Minimum W (kN) & 37.8 & 35.3 & 49.1 & 35.2 & 181.7 & 164.5 & 198.1 & 153.6 \\
Max. story drift (mm) & 3.6 & 1.2 & 9.6 & 9.6 & 7.4 & 4.8 & 8.1 & 9.1 \\
Max. total drift (mm) & 11.8 & 4 & 29.4 & 28.9 & 42.8 & 31.3 & 51.4 & 50.6 \\
Max. PMM ratio & 0.95 & 0.92 & 0.45 & 0.94 & 0.93 & 0.96 & 0.70 & 0.78 \\
Max. iteration & 1000 & 1000 & 1000 & 1000 & 1000 & 1000 & 1000 & 1000 \\
\hline
\end{tabular}

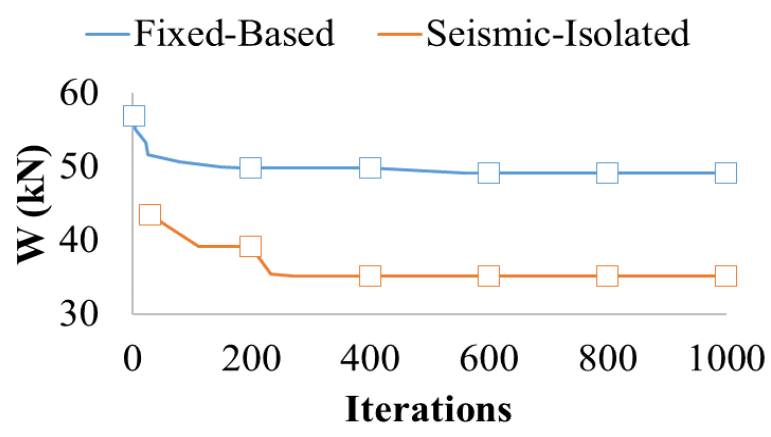

Fig. 7. Design histories of the $\mathrm{ABC}$ algorithm for 4-story frame without braces

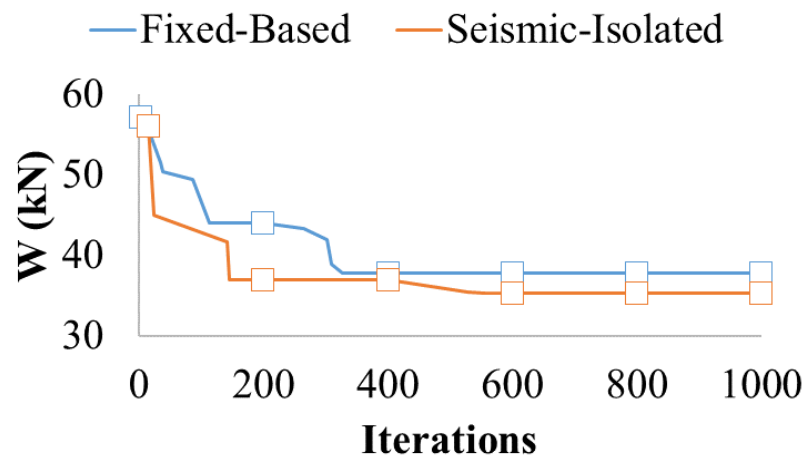

Fig. 8. Design histories of the $\mathrm{ABC}$ algorithm for 4-story frame with braces 


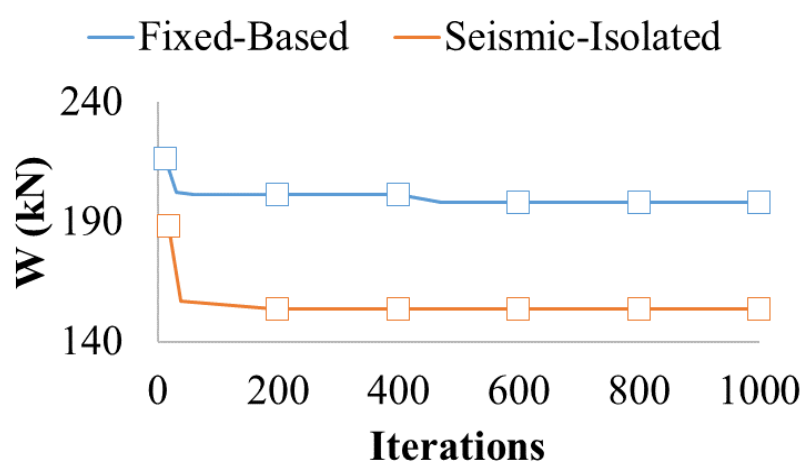

Fig. 9. Design histories of the $\mathrm{ABC}$ algorithm for 8-story frame without braces

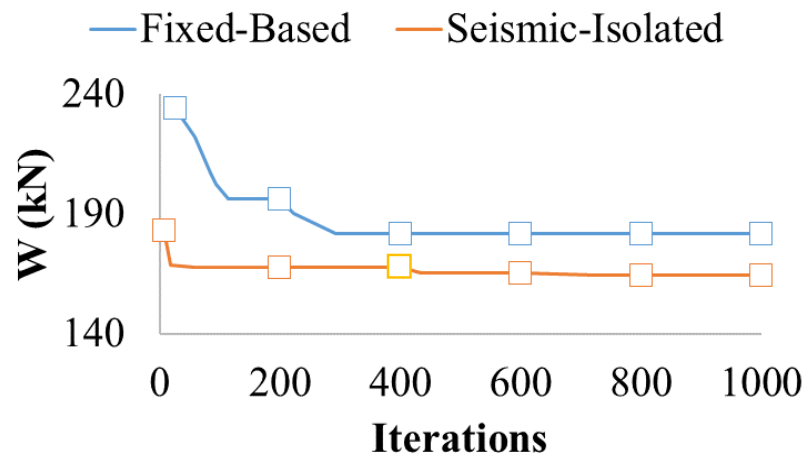

Fig. 10. Design histories of the ABC algorithm for 8-story frame with braces

\section{Summary and Conclusions}

To investigate the effect of seismic isolation on optimum weight of superstructures, 8 steel plane frame examples, which are considered as fixed-based and seismic-isolated, are tested. The frames are diversified as related to story height and bracing. TFP isolator devices are used for the seismic isolation. An optimization program developed as based on the ABC algorithm is employed to obtain the optimum structural weight values. The frame examples are designed in a way to satisfy strength, inter-story drift, top-story drift and geometric requirements that are implemented from LRFD-AISC. The following conclusions are drawn from the conducted study:

- The optimization program developed based on the ABC algorithm is well-performed with a consistent convergence rate and proximity to the limitations.

- For the examples with braces, the most effective design constraints are PMM ratios, while for the examples without braces, the most effective design constraints are story drift limitations.

- In the frame examples with braces, the drift values are far from the limit values. Therefore, the drift limitations are not very effective and the efficiency of the seismic isolation is not sufficient. On the other hand, the drift limitations are highly effective in the unbraced frame examples and the seismic isolation is very effective.

- It is observed that the weight advantage of the designs dominated by drift limitations is much higher than ones dominated by the PMM ratios. 
- The seismic isolation offers more advantage in the unbraced frames rather than the braced ones in terms of the weight because drift limitations are more dominated than the other limitations in terms of weight reduction. Seismic isolation decreases story drift values of superstructure. Accordingly, seismic isolation is not so effective in braced frames because braces already restrict the story drifts of the structure so that the structure cannot approach the drift limits. Therefore the effect of drift is not seen for the optimum weight solution of seismic-isolated braced frames.

In the study, it is seen that the seismic isolation generally offers a weight advantage depending on the drift values, and it is understood that this advantage is much lower than the drift effect for the PMM values. However, the lateral drifts in irregular and 3-D structures result in undesirable effects such as torsion, and in these types of structures, the effect of seismic isolation on optimum design can be seen better. In the light of these assumptions, the effect of seismic isolation on the optimal design of 3-D structures is thought to be done in future studies. Although the design based on seismic isolation offers a cost advantage, this advantage can be lost when the cost of the isolator devices is taken into account. A more realistic comparison is made if the structure is optimized together with the cost of the isolator devices. Such a study is planned to be conducted in the future.

\section{References}

[1] Dillen, W., Lombaert, G., and Schevenels, M., A hybrid gradient-based/metaheuristic method for Eurocode-compliant size, shape and topology optimization of steel structures, Engineering Structures, 239, 112137, 2021.

[2] Ficarella, E., Lamberti, L., and Degertekin, S.O., Comparison of three novel hybrid metaheuristic algorithms for structural optimization problems, Computers and Structures, 244, 106395, 2021.

[3] Gonçalves, M.S., Lopez, R.H., and Fleck Fadel Miguel, L., Search group algorithm: A new metaheuristic method for the optimization of truss structures, Computer and Structures, 153, 165-184, 2015.

[4] Jahangiri, M., Hadianfard, M.A., Najafgholipour, M.A., Jahangiri, M., Gerami, M.R., Interactive autodidactic school: A new metaheuristic optimization algorithm for solving mathematical and structural design optimization problems, Computer and Structures, 235, $106268,2020$.

[5] Tran-Ngoc, H., Khatir, S., Ho-Khac, H., De Roeck, G., Bui-Tien, T., Abdel Wahab, M., Efficient Artificial neural networks based on a hybrid metaheuristic optimization algorithm for damage detection in laminated composite structures, Composite Structures, 262, $113339,2021$.

[6] Fleck Fadel Miguel, L., Fleck Fadel Miguel L., Shape and size optimization of truss structures considering dynamic constraints through modern metaheuristic algorithms, Expert Systems with Applications, 39, 9458-9467, 2012.

[7] Aydoğdu, İ., Akın, A., Saka, M.P., Design optimization of real world steel space frames using artificial bee colony algorithm with Levy flight distribution, Advances in Engineering Software, 92, 1-14, 2016. 
[8] Jawad, F.K.J., Ozturk, C., Dansheng, W., Mahmood, M., Al-Azzawi, O., Al-Jemely, A., Sizing and layout optimization of truss structures with artificial bee colony algorithm, Structures, 30, 546-559, 2021.

[9] Skandalos, K., Afshari, H., Hare, W., Tesfamariam, S., Multi-objective optimization of inter-story isolated buildings using metaheuristic and derivative-free algorithms, Soil Dynamics and Earthquake Engineering, 132, 106058, 2020.

[10] Tsipianitis, A., Tsompanakis, Y., Optimizing the seismic response of base-isolated liquid storage tanks using swarm intelligence algorithms, Computers and Structures, 243, 106407, 2021.

[11] Çerçevik, A.E., Avşar, Ö., Hasançebi, O., Optimum design of seismic isolation systems using metaheuristic search methods, Soil Dynamics and Earthquake Engineering, 131, $106012,2020$.

[12] Peng, Y., Ma, Y., Huang, T., De Domenico, D., Reliability-based design optimization of adaptive sliding base isolation system for improving seismic performance of structures, Reliability Engineering and System Safety, 205, 107167, 2021.

[13] Rizzian, L., Leger, N., Marchi, M., Multiobjective sizing optimization of seismic-isolated reinforced concrete structures, Procedia Engineering, 199, 372-377, 2017.

[14] Jiang, L., Zhong, J., Yuan, W., The pulse effect on the isolation device optimization of simply supported bridges in near-fault regions, Structures, 27, 853-867, 2020.

[15] LRFD-AISC, Manual of steel construction, In: "Load and Resistance Factor Design", Third Edition, AISC, I\&II, 2001.

[16] Ad Hoc Committee on Serviceability, Structural serviceability: A critical appraisal and research needs, Journal of Structural Engineering, ASCE, 112(12), 2646-2664, 1986.

[17] Karaboga, D., An idea based on honey bee swarm for numerical optimization, Technical Report-TR 06, 2005.

[18] Karaboga, D., Basturk, B., A powerful and efficient algorithm for numerical function optimization: artificial bee colony (ABC) algorithm, Journal of Global Optimization, 39, 459-471, 2007.

[19] Basturk, B., Karaboga, D., An artificial bee colony (ABC) algorithm for numeric function optimization, Proceedings of IEEE Swarm Intelligence Symposium, Indianapolis, Indiana, USA, 12-14 May 2006.

[20] Karaboga, D., Basturk, B., Artificial bee colony (ABC) optimization algorithm for solving constrained optimization problems, IFSA 2007: Foundations of Fuzzy Logic and Soft Computing, LNCS: 4529, 789-798, 2007.

[21] Karaboga, D., Basturk, B., On the performance of artificial bee colony (ABC) algorithm, Applied Soft Computing, 8(1), 687-697, 2008.

[22] Karaboga, D., Akay, B., A modified artificial bee colony (ABC) algorithm for constrained optimization problems, Applied Soft Computing, 11, 3021-3031, 2011.

[23] Karaboga, D., Gorkemli, B., Ozturk, C., Karaboga, N., A comprehensive survey: artificial bee colony (ABC) algorithm and applications. Artificial Intelligence Review, 42, 21-57, 2014.

[24] Constantinou, M.C., Kalpakidis, I., Filiatrault, A., Ecker Lay, R.A., LRFD-Based analysis and design procedures for bridge bearings and seismic isolators, Technical Report, 2010. 